Kai A. Konrad

\title{
Large Investors, Regulatory Taking and Investor-State Dispute Settlement ${ }^{1}$
}

\section{Max Planck Institute for Tax Law and Public Finance \\ Working Paper 2016 - 10}

November 2016

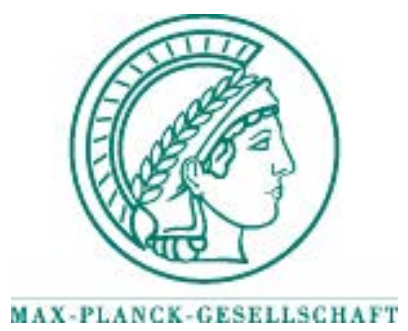

Max Planck Institute for Tax Law and Public Finance

Department of Business and Tax Law

Department of Public Economics

http:/ / www.tax.mpg.de 
Working papers of the Max Planck Institute for Tax Law and Public Finance Research Paper Series serve to disseminate the research results of work in progress prior to publication to encourage the exchange of ideas and academic debate. Inclusion of a paper in the Research Paper Series does not constitute publication and should not limit publication in any other venue. The preprints published by the Max Planck Institute for Tax Law and Public Finance represent the views of the respective author(s) and not of the Institute as a whole. Copyright remains with the author(s).

Max Planck Institute for Tax Law and Public Finance

Marstallplatz 1

D-80539 Munich

Tel: $\quad+498924246-0$

Fax: $\quad+498924246-501$

E-mail: ssrn@tax.mpg.de

http://www.tax.mpg.de 


\title{
Large investors, regulatory taking and investor-state dispute settlement
}

\author{
Kai A. Konrad* \\ May 9, 2017
}

\begin{abstract}
This paper offers an economic analysis of an international investorstate dispute settlement regime (ISDS) in markets with large investors. It identifies a reason for strategic overinvestment by the domestic industry, leading to permissive regulation in the absence of ISDS. An "ideal" investor-state dispute settlement arrangement (efficiency- oriented, transaction-cost free, with untouchable, fully reliable, and unbiased judges) has positive and negative effects in this framework. It generates an equal level playing field for domestic and foreign investors, but it magnifies an existing overinvestment problem and may reduce world welfare. The results explain anecdotal evidence according to which ISDS that protects foreign investors is liked by the domestic industry and disliked by other interest groups in the host country.

Keywords: Investment arbitration, settlement courts, time-consistent regulation, strategic investment

JEL classification numbers: Q68, K11, F21, F55

${ }^{*}$ Correspondence address: Kai A. Konrad, Max Planck Institute for Tax Law and Public Finance, Marstallplatz 1, D-80539 Munich, Germany. E-mail: kai.konrad@tax.mpg.de. This is a revised version of a draft entitled "Large investors and permissive regulation: Why environmentalists may dislike investor-state dispute settlement". Research assistance by Niklas Gebhard and very helpful comments by Alexander Wu, Harald Lang, Thomas Tangerås and two anonymous reviewers are gratefully acknowledged. The usual caveat
\end{abstract} applies. 


\section{Introduction}

This paper studies the nexus between strategic investors, risks and other spillovers from industrial production, government regulation, and a regime with international investor-state dispute settlement courts (ISDS). It identifies an existing regulatory policy failure that is caused by large domestic investors and time-consistent regulatory policy in the absence of ISDS and shows that ISDS can magnify this problem.

Investor-state arbitration has generated considerable interest in the legal sciences. Franck and Wylie (2015) review the role of, and the previous discussion about, investor-state dispute settlement arrangements such as investment treaty arbitration courts. There is agreement on their economic relevance and importance. The establishment and design of ISDS is, for instance, a key aspect of many free-trade agreements. But ISDS is even more widespread. Almost 700 disputes were initiated between 1987 and 2015. Governments were most frequently challenged not only for regulatory takings in the sector of renewable energy, but also for direct expropriations, discriminatory treatment, revocation and denial of licenses or permits (see the Unctad World Investment Report 2016, pp. 104-106).

Conceptually, ISDS addresses a fundamental policy problem in the international context: Foreign investors who install major physical capital in a sovereign host country suffer from the threat that the host country may use its sovereignty to appropriate from the foreign investor. Means to do this are manifold: discriminatory regulation, confiscatory taxation, arbitrary fines, extortionary threats, and blunt expropriation or nationalization. The seminal contributions by Eaton and Gersovitz (1983), followed by Cole and English (1991), Thomas and Worrall (1994) and others, have alluded to this problem and its implications. Foreign investors shy away from making investments in a particular country if they anticipate opportunistic time-consistent confiscatory policy by the government in the host country of their investment. A punch line from this literature is that it would be in the mutual interest of foreign investors and of the host country, but difficult, to tie the hands of 
the sovereign host government. ${ }^{1}$ The design of a regime with ISDS is meant to solve this problem by protecting foreign investors and by enforcing their property rights. It allows them to take the host-state to a court that is outside the control of the host-state government, but makes rulings which are binding for the parties in the dispute.

Some dark sides of ISDS have also been identified. Von Bogdandy and Venzke (2014) allude to the lack of democratic legitimacy. The courts, while meant to tie the hands of sovereign governments, would need to be controlled and supervised as well - but by whom? In the absence of benevolence, interest policy and corruption might flourish. The court rulings may become arbitrary, their judgements may lack precision and predictability, and the sovereign states themselves may become the victims of extortion. Franck and Wylie (2015) provide an excellent collection of negative views - according to which these courts are pro-investor biased, unpredictable or illegitimate and how states reacted to this. ${ }^{2}$

The positive effects of ISDS that have been identified rely on a wellfunctioning ISDS mechanism, whereas criticism mostly relies on possible deficiencies or the malfunctioning of the regime with ISDS, some of which could be remedied. ${ }^{3}$ So, is the desirability of ISDS only a question of the quality

\footnotetext{
${ }^{1}$ Dixit (2011) offers a survey about results on the quantitative importance of incomplete investor protection and discusses protection mechanisms. A few mechanisms have been identified. Repeated play is important, as noted by Eaton and Gersovitz (1983). Also incomplete information about the cost of production and relocation may protect some investor rent (Konrad and Lommerud 2001, Olsen and Osmundsen 2003). The same applies for strategic capacity overinvestment across multiple locations (Janeba 2000). Whether the type of political regime is important for limiting opportunism has also been discussed (Huck and Konrad 2005).

${ }^{2}$ Sappideen and He (2015) discuss several countries' shifting position and a number of cases that were triggered by governmental consumer- and environmental protection regulation.

${ }^{3}$ Rivkin et al. (2015) discuss many of the conceptual issues that had to be solved for a well-functioning ISDS. "Ideal" ISDS procedures, reliably predictable, accurate, uncorrupted, and transaction-cost free ISDS that is fair and equitable and strikes a balance between investor protection and legitimate regulatory takings would not be affected by most of the criticism mentioned.
} 
of its design? This question is studied here in a system that, by design, is transaction-cost free, makes fully well-thought-out and benevolent decisions, is free of outcome uncertainty or problems of incomplete information and perfectly and precisely follows a decision rule and compensation rule that is efficiency-guided. Still a "dark side" can be identified: ISDS magnifies incentives for strategic overinvestment and excessively permissive regulation that can emerge in industries with major set-up costs and large strategic investors.

In a nutshell, regulatory policy decides whether or not production in a given industry may take place. This policy, if chosen by a benevolent government, may aim at efficiency at the point of time of decision-making. Information about consumer risks, environmental risks, and other spillovers may arrive between the time of private investment ("ex ante") and the time when the regulatory decision must be made ("ex post"). A government will base its regulatory decisions on the costs and benefits of production that apply and are available at the point of time when the regulatory decision is being made. If large investors have installed huge productive capacities that allow for large-scale, cost-efficient production, then a restrictive regulatory policy sacrifices the huge producer rents that could otherwise emerge from this investment. This high opportunity cost will make the government's regulatory policy more permissive than otherwise. The amount of investment influences future regulatory policy. This, in turn makes the industry's investment choice a strategic variable: domestic investors may have an additional, strategic incentive to make a high investment.

In the absence of ISDS the government regards the loss of producer rents for the domestically-owned industry, but it disregards the loss of producer rents of the foreign investors. If ISDS is in place and operating, it may force the government to compensate the foreign investors for these lost producer rents. The host government internalizes these costs and, as a result, becomes more permissive. Hence, the foreign investor becomes strategic as well. Moreover, the investments undertaken by several investors are complements to each other: high investment by one investor makes regulatory policy more permissive, and this benefits the other investor and makes this 
other player's investment more worthwhile.

The analysis makes several predictions. First, large domestic investors have a strategic effect on the government's regulatory choice. This strategic effect leads to excessive investment in the absence of ISDS. Second, ISDS will also install this strategic incentive for large foreign investors. This leads to more investment. Third, strategic complementarity of the investment amounts leads to even more investment. Fourth, in turn, the high investment ultimately contributes to regulation that is, from an ex-ante point of view, overly permissive. Fifth, Quick (2015, pp. 199-200) reports that "political groups, in particular the social democrats, trade unions, customer organizations and other NGOs oppose the inclusion of ISDS in TTIP for various reasons," but that "only the business community supports ISDS." The theory predictions here are in line with this empirical observation.

The findings contribute to the economic literature on international arbitration courts. Some early contributions focus on the courts' role in the settlement of disputes between players from the private sector (see, for instance, Casella, 1996, Mattli, 2001, Dixit, 2011). Pioneering work by Aisbett, Karp and McAusland (2010a) provides a contract theory study of regulatory takings when the government is exempt from paying compensation if and only if the court perceives that the social benefits from regulation are sufficiently high. Their analysis relates to the institutional context of the North American Free Trade Agreement (NAFTA). Aisbett, Karp and McAusland (2010b) study the optimal compensation contract more generally. Stähler (2016) also considers how to improve ISDS by using mechanism design. Janeba (2016) considers how national welfare in a possible host country depends on whether investor-state dispute settlement devices are introduced unilaterally or simultaneously and bilaterally. Kohler and Stähler (2016) analyze the role of investor-state dispute settlements in a two-period model where the government wants to attract foreign investment, but where this government is tempted to re-regulate business once the investment has taken place. The time-consistency problem they address is related to the one discussed in the earlier literature on the hold-up problem in foreign direct investments, where the generic problem is that the hold-up problem may cause 
too low investment. In contrast, this paper studies strategic investors rather than opportunistic governments. Horn and Tangerås (2016) consider mutual investment agreements with ISDS between symmetric and asymmetric countries in a very rich framework. They concentrate mostly on the case in which individual firms are small and take the (equilibrium) probability of regulation as given but an extension also considers a foreign monopoly firm. Their research focus is on the optimal compensation contract. Our framework unveils a strategic complementarity between a domestic and a foreign firm in their attempts to reduce regulatory threat, and how ISDS which implements ex-post efficiency affects this interaction.

The analysis proceeds as follows. Section 2 relates the problem to existing theoretical and empirical analyses of firms' investment choices that try to influence government regulation and anecdotal evidence from the energy sector. Section 3 outlines the general framework. Section 4 studies the game in the absence of ISDS. Section 5 studies the equilibrium with ISDS. Section 6 compares the regimes, and a final section concludes.

\section{Relevance}

An important question is whether the investment channel is an important means to influence government behavior. Some theoretical claims have been made in related contexts. Damania (2001) studies the role of investment choice to influence governmental environmental regulation. The key of the argument is that the government might accommodate its environmental regulation if the industry did not adopt clean technologies but remained heavily invested in a dirty technology. Glazer and Janeba (2004) make a related point about environmental regulation in the automobile industry. According to them, the US car industry used investment choices to try to influence the choice of environmental norms. Dijkstra (2007) develops a model of competition between an externality generating industry and the interest group suffering from this externality. The key aspect in his analysis is that the benevolent regulatory choice of the government will depend on the strategic 
investments made by the two groups. He illustrates the argument in the context of noise regulation at Schipol airport. Bloningen and Figlio (1998) try to quantitatively assess strategic investment in the context of foreign direct investment. They ask whether large stocks of foreign direct investment affect legislation on foreign trade protection. Further empirical work, supporting the idea that investment influences regulatory policy, is Cole, Elliott and Fredriksson (2006) who find evidence that additional FDI can weaken environmental regulation, particularly in countries with high corruption.

The pharmaceutical industry and the regulation of admission of new products, and whether treatment should be covered by health insurance may be another important application. ${ }^{4}$ In line with a time-consistent approach, Cutler and Ericson (2010) discuss the social perspective for cost-effectiveness analysis and favour a normative benchmark that compares the health benefits on one side and the sum of marginal production cost and the monopoly producer rent on the other. At the point when the regulatory decision is made, this time-consistent efficiency oriented cost-benefit decision making disregards the considerable sunk cost of innovation and medical research. One may argue that this may lead to an admission policy that is too lenient from an ex-ante point of view, and may invite too much innovation/research.

In a different, but related context, Robinson (2005) addresses the question whether squatters or other illegal land users may invest in the occupied land in order to make eviction by the government less likely. This investmentexpropriation problem has a flavor similar to the investment-regulation case without ISDS. Her theory results are ambiguous and hinge on the parameters of her model. ${ }^{5}$ Her survey of the empirical literature on this topic shows mixed results and points at difficult endogeneity problems, but her anecdotal evidence is in support of strategic investment. ${ }^{6}$

\footnotetext{
${ }^{4}$ I am grateful to a reviewer who kindly suggested this example.

${ }^{5}$ Results are more straightforward, and overinvestment incentives apply if the evicting government has to compensate the land users at the full market value. The misleading incentives of such a compensation policy has been discussed in a seminal paper by Blume, Rubinfeld and Shapiro (1984) and are avoided in our context by the design of the compensation policy.

${ }^{6}$ Robinson (2005, p. 154) also reports the following anecdote from a field study in
} 
The relevance of our analysis may be particularly high in the area of nuclear energy industry. When the major part of the investment in nuclear power plants was made, the uncertainty over the size of possible negative externalities (e.g., environmental risks, burden on future generations, hazards for life and health) associated with this technology was large. There was also some initial euphoria about possibly major positive spillovers (e.g., R\&D spillovers, political independence from crude oil). The incidents at Chernobyl and Fukushima revealed that the downside risks are sizeable. Governments assessed and reconsidered the costs and benefits and had to decide whether the use of the technology should be continued or not. The heterogeneity of investment levels (in relation to the country's size of the economy) was considerable inside the OECD. Exiting from this technology was more expensive for countries with heavy investments in nuclear energy. Hence, a country's decision to exit should be positively correlated with a low investment level.

Italy/Sweden: After Chernobyl, Italy was one of the OECD countries that relied less heavily on nuclear power in 1985 (the year of the Chernobyl incident) and decided to exit. Italy's phase-out decision followed a referendum in 1987 and was completed in 1990. Sweden is one of the countries which had most heavily invested in nuclear power energy prior to 1985 . Several attempts were made there to initiate a phase-out — and they all failed. Given the dominant role of nuclear power energy there, the cost per citizen would have been much higher than in Italy (see Schneider and Froggatt, 2014, for country reports).

France/Germany: Germany and France both hosted substantial capital stocks in the form of nuclear power plants and both countries did not exit right after Chernobyl. Germany relied less heavily on nuclear power than France, however. In Germany, the nuclear power sector is smaller and ownership in the nuclear energy-producing companies is more widely dispersed,

Karnataka: "A state government official himself confirmed unofficially that once a farmer had invested heavily on encroached land, it might be better to give or sell the farmer the land, that is, to regularize the encroachment, rather than go through the cost and uncertainty of trying - not always successfully - to evict the farmer (Karnataka State Official from Forestry Department, personal communication, 1995)." 
nationally and internationally. ${ }^{7}$ After the Fukujima accident in 2011 France did not dramatically change its policy, whereas Germany chose a strongly accelerated exit only a few days after the event (Schneider and Froggatt, 2014, for country reports).

The differences in policy choices made in the aftermath of these accidents may have many reasons, but these choices are in line with the theory developed in this paper: a larger investment in a given technology provides the industry with more protection against regulatory threat.

ISDS plays a major role in the nuclear energy sector. Germany's accelerated phase-out decision right after the Fukujima accident is an example. The government's regulatory exit decision expropriated the owners of the power plants and caused a loss of their producer rents. The Swedish-owned Vattenfall company initiated a dispute at an international arbitration court. These disputes are confidential, but the size of the claim made, US $\$ 5.8$ billion plus 4 percent interest, was leaked (see Bernasconi-Osterwalder and Brauch, 2014). ${ }^{8}$

\section{The framework}

Players The game has three players and three decision stages. Two firms choose whether and how to invest in a given host country. One of the firms is owned by residents in the host country. This firm is denoted as $D$ (for "domestic"). The other firm is foreign-owned and denoted as $F$ (for "foreign").

\footnotetext{
${ }^{7}$ Moreover, in France, the major electricity producer Électricité de France is government-owned. A sudden exit would cause large immediate and direct windfall losses for the French government. In Germany, the energy companies are stock companies with a partially foreign ownership, and some power plants are owned by Vattenfall, an affiliate of the Swedish energy producer. Abandoning nuclear power would not harm the government in Germany as directly or to the same extent as in France.

${ }^{8}$ As reported by Rivkin et al. (2015, p.131), ISDS is particularly prominent in the context of the energy sector. More than one third of the arbitration cases between 1972 and 2012 were cases related to the energy sector, and disputes involving oil, gas, and mining account for more than one third of the cases registered in the Caseload Statistics of the International Centre for Settlement of Investment Disputes (ICSID).
} 
The firms' investments technically enable them to produce and supply in a market for a good at a later stage. Once they have invested, new information on the external costs and benefits of the firms' technology becomes available. Then the government in the host country has to decide whether or not they are allowed to produce. The government makes this regulatory decision and bases it on the production facilities, on current information on the side effects if production takes place, and on whether ISDS exists and is operative. Then, depending on this decision, production may take place.

Actions and sequencing In stage 1 the two investors choose investment expenditures denoted by $k_{D} \geq 0$ and $k_{F} \geq 0$. These can be seen as capital stocks that will later facilitate production of output. The cost of this investment is

$$
K_{D}\left(k_{D}\right)=\frac{1}{2} k_{D}^{2} \text { and } K_{F}\left(k_{F}\right)=\frac{1}{2} k_{F}^{2} .
$$

These cost functions are convex and are the same for both firms.

Firm activity has an external cost of size $\theta$. It is normalized to zero if the firms do not produce and is equal to a fixed, output-size independent amount $\theta$ if they produce. ${ }^{9}$ It measures the size of the sum of negative externalities (e.g. consumer risks, environmental risks) net of positive externalities (e.g., technological spillovers). Hence, a positive cost parameter $\theta$ describes an outcome in which the negative externalities exceed the positive externalities. The $\theta$ is a draw from a random distribution with a cumulative distribution function $G(\theta)$. The function $G(\theta)$ is already public information at stage 1 and prior to firms' investment. Let us assume that

$$
G(\theta)=\frac{1}{2}+\frac{\theta}{a}
$$

with support $\theta \in\left[-\frac{a}{2},+\frac{a}{2}\right]$, and $a>5 / 4 .{ }^{10}$ The precise value of $\theta$ becomes common knowledge once the investments are made at the end of stage 1.

\footnotetext{
${ }^{9} \mathrm{~A}$ fixed-cost component is important for the analysis, but we may allow for an additional proportional-cost component.

${ }^{10}$ This assumption is (together with the assumptions about $\pi_{i}$ and $K_{i}$ ) sufficient to fulfill globally the second-order condtions in the maximization problems of $D$ and $F$ in the regimes $\mathrm{N}$ and ISDS and to yield thresholds $\theta^{*}$ as in (19) and $\hat{\theta}$ as in (32) in the two regimes
} 
In stage 2 , based on the observed levels of investments $k_{D}, k_{F}$ and the value of $\theta$, the government in the host country decides whether the two firms will be allowed to produce or whether production will be banned. This decision is a zero-one decision, denoted by

$$
\nu\left(k_{D}, k_{F}, \theta\right)=\left\{\begin{array}{cc}
1 & \text { if the government admits production } \\
0 & \text { if the government bans production. }
\end{array}\right.
$$

If the government admits production $(\nu=1)$, the game enters into stage 3. Firms choose the quantities they produce. Let us denote these quantities by $x_{D} \geq 0$ and $x_{F} \geq 0$. The cost of production is

$$
C_{i}\left(x_{i}\right)=\frac{1}{k_{i}} \frac{1}{2} x_{i}^{2}
$$

Production cost is quadratic in output quantity, and a higher capital investment reduces the production cost of a given quantity.

If the government admits production $(\nu=1)$ then the market opens. The two firms choose quantities $x_{D}$ and $x_{F}$ and sell them at the exogenously given world market price $q=1$. This ends the game.

This set-up removes consideration of changed consumer rents or of market power and duopoly competition. The production of electricity for a large international market in nuclear power plants may serve as an instructive example that may approximately conform with these assumptions.

The set-up here uses parametric forms in (1) and (4) and (2). These assumptions are chosen in order to obtain closed-form solutions. The appendix adopts more general assumptions about production technology and the random distribution of external costs and discusses consumer-rent effects and market-power effects.

Two regimes Whether ISDS exists does not affect the production choice if $\nu=1$. If, instead, the government bans production $(\nu=0)$, then $x_{D}=x_{F}=$ for the government's regulation choice that are inside the support of $\theta$. If the support of $\theta$ shrinks or shifts sufficiently, firms may be in a corner solution with no investment and production, or in which the investment is so high that $G\left(\theta^{*}\right)=1$, or $G(\hat{\theta})=1$ such that the marginal incentive for strategic investment is not operative. 
0. The existence of ISDS makes a difference in this case and two regimes need to be distinguished:

The regime $N$ - without ISDS. The firms are not compensated for the loss in producer rent that is caused by the production ban. This ends the game.

The regime ISDS - with ISDS in operation. The foreign firm $F$ appeals to the court and requests compensation. ${ }^{11}$ The arbitration court is a costless, transaction-cost-free automated decision-maker. The court calculates the following threshold for the size of the externality:

$$
\hat{\theta}=\pi_{D}^{*}\left(k_{D}\right)+\pi_{F}^{*}\left(k_{F}\right) .
$$

The terms $\pi_{D}^{*}\left(k_{D}\right)$ and $\pi_{F}^{*}\left(k_{F}\right)$ denote the maximum producer rents which $D$ and $F$ could attain if production took place and will be determined further below. These producer rents are functions of the amounts $k_{D}$ and $k_{F}$ invested. Now, for $\nu=0$ and $\theta>\hat{\theta}$ the court rules in favor of the government, and no compensation needs to be paid to firm $F$. For $\nu=0$ and $\theta \leq \hat{\theta}$ the court decides that compensation of size $\pi_{F}^{*}\left(k_{F}\right)$ has to be paid to $F$. The court judgement is deterministic and follows a simple logic: For $\theta>\hat{\theta}$, the cost of the externality exceeds the sum of all producer rents that would accrue if the firms were allowed to produce. Hence, if $\theta>\hat{\theta}$ the government should ban production in the interest of world welfare. For $\theta \leq \hat{\theta}$ world welfare is maximized if the firms are allowed to produce: the producer rents exceed the externality costs. If the government nevertheless bans production in this case, then the firm $F$ can (and will) costlessly appeal to the court and the court forces the government to compensate firm $F$ with an amount that is exactly equal to the firm's loss in producer rent $\pi_{F}^{*}$. This logic explains why the threshold $\hat{\theta}$ in (5) implements ex-post efficient governmental decisionmaking.

\footnotetext{
${ }^{11}$ We can also have an additional decision stage in which the foreign firm may decide whether or not to activate the court. Due to the precise and deterministic decision rule, the court would never be activated in the equilibrium. The error-free decision rule is assumed here to remove a possible shortcoming of ISDS from the picture. For a departure from this assumption and some of the important implications see Janeba (2016).
} 
A variety of different compensation rules is implemented as part of the various existing trade agreements. The ISDS regime described here is probably not the one most widely used. Rather, it is chosen here because it implements ex-post-efficiency-oriented compensation decisions by the court: compensation has to be paid if and only if, at the time the regulatory decision is made, the decision is not in line with what would be most efficient for overall welfare. This ISDS regime is also subject to time-consistent decisionmaking. But rather than focusing on ex-post welfare in the host country, the court focuses on ex-post world welfare. ${ }^{12}$ The approach here is in the spirit of Aisbett, Karp and McAusland (2010b) who describe it (p. 369) as "legally known as a PPCO - a rule under which the regulator is exempt from paying compensation if and only if the court perceives that the social benefits from regulation are sufficiently high."

Payoffs in the Regime N (without ISDS) Firm D's payoff in regime $N$ is

$$
\Pi_{D}=\left\{\begin{array}{cc}
x_{D}-\frac{1}{k_{D}} \frac{1}{2} x_{D}^{2}-\frac{1}{2} k_{D}^{2} & \text { if } \nu=1 \\
-\frac{1}{2} k_{D}^{2} & \text { if } \nu=0 .
\end{array}\right.
$$

For a given decision $\nu$ firm $D^{\prime}$ payoff does not depend on whether ISDS is operative. The decision $\nu$, however, will depend on the regime. Firm $F$ 's payoff in regime $N$ is

$$
\Pi_{F}^{N}=\left\{\begin{array}{cc}
x_{F}-\frac{1}{k_{F}} \frac{1}{2} x_{F}^{2}-\frac{1}{2} k_{F}^{2} & \text { if } \nu=1 \\
-\frac{1}{2} k_{F}^{2} & \text { if } \nu=0 .
\end{array}\right.
$$

The host government's payoff in this regime is

$$
\Omega^{N}=\left\{\begin{array}{cc}
x_{D}-\frac{1}{k_{D}} \frac{1}{2} x_{D}^{2}-\frac{1}{2} k_{D}^{2}-\theta & \text { if } \nu=1 \\
-\frac{1}{2} k_{D}^{2} & \text { if } \nu=0 .
\end{array}\right.
$$

\footnotetext{
${ }^{12}$ The assumption about a compensation rule that is based on whether or not the government's decision is maximizing ex-post welfare is in conformity with the optimal-contractdesign results in a parallel paper by Horn and Tangerås (2016) for the case of many small firms. They also consider firms' market power in an extension. An ex-ante optimal efficiency-oriented compensation rule would require that the specific compensation rule depends on whether firms have market power or not.
} 
It consists of the producer rent of the domestic firm $D$ minus the external cost $\theta$ and minus the sunk cost of $D$ if production takes place, and of the sunk investment cost of $D$ in case production is banned.

Payoffs in the ISDS regime In regime ISDS an arbitration court is in operation. The payoff of firm $D$ is still given by (6). It is not directly affected by the arbitration court, as $D$ does not receive any compensation.

Firm F's payoff is

$$
\Pi_{F}^{I S D S}=\left\{\begin{array}{cll}
x_{F}-\frac{1}{k_{F}} \frac{1}{2} x_{F}^{2}-\frac{1}{2} k_{F}^{2} & \text { if } \nu=1 & \\
-\frac{1}{2} k_{F}^{2} & \text { if } \nu=0 & \text { and } \theta>\hat{\theta} \\
\pi_{F}^{*}\left(k_{F}\right)-\frac{1}{2} k_{F}^{2} & \text { if } \nu=0 & \text { and } \theta \leq \hat{\theta}
\end{array} .\right.
$$

A comparison between $\Pi_{F}^{N}$ and $\Pi_{F}^{I S D S}$ shows: if the government permits production, firm $F$ 's profit depends on investment and output, but not on the ISDS regime (first lines in (7) and (9)). The regime matters if production is banned. In regime $N$, if production is banned, the firm $F$ has no producer rents. It does not receive a compensation for these forgone producer rents if the externality $\operatorname{cost} \theta$ exceeds $\hat{\theta}$, and receives a compensation that is equal to the maximum producer rent $\pi_{F}^{*}\left(k_{F}\right)$ if the externality cost $\theta$ does not exceed $\hat{\theta}$.

The payoff of the host government in the ISDS regime is equal to the sum of the rents that accrue to the host country:

$$
\Omega^{I S D S}=\left\{\begin{array}{ccc}
x_{D}-\frac{1}{k_{D}} \frac{1}{2} x_{D}^{2}-\frac{1}{2} k_{D}^{2}-\theta & \text { if } \nu=1 \\
-\frac{1}{2} k_{D}^{2} & \text { if } \nu=0 \text { and } \theta>\hat{\theta} \\
-\pi_{F}^{*}\left(k_{F}\right)-\frac{1}{2} k_{D}^{2} & \text { if } \nu=0 \text { and } \theta \leq \hat{\theta}
\end{array}\right.
$$

The government's payoff $\Omega^{I S D S}$ includes the producer rent of the domestic firm. The externality $\operatorname{cost} \theta$ that emerges if the government allows production is also part of the government's payoff. Furthermore, it accounts for compensation payments $-\pi_{F}^{*}\left(k_{F}\right)$ to the foreign firm $F$ that are imposed if $\nu=0$ and $\theta \leq \hat{\theta}^{13}$

\footnotetext{
${ }^{13} \mathrm{By}$ construction, the two firms do not generate consumer rents here. Positive con-
} 


\section{The equilibrium without ISDS}

This subsection solves the game for the regime $N$ by backward induction and starts at stage 3 . If $\nu=0$ then no decisions have to be made, no production takes place, no externality cost applies. Payoffs are equal to $\Pi_{D}^{N}=-\frac{1}{2} k_{D}^{2}$ for firm $D, \Pi_{F}^{N}=-\frac{1}{2} k_{F}^{2}$ for firm $F$, and equal to $\Omega^{N}=-\frac{1}{2} k_{D}^{2}$ for the government.

If $\nu=1$, then each firm $i \in\{D, F\}$ maximizes its individual producer rent

$$
\pi_{i}=x_{i}-\frac{1}{k_{i}} \frac{1}{2} x_{i}^{2}
$$

For a given $k_{i}$ the quantity $x_{i}$ that maximizes this producer rent is $x_{i}^{*}=k_{i}$. Inserting this into (11) yields

$$
\pi_{i}^{*}\left(k_{i}\right)=\frac{k_{i}}{2}
$$

and payoffs $\pi_{i}^{*}\left(k_{i}\right)-K_{i}\left(k_{i}\right)=\frac{1}{2} k_{i}-\frac{1}{2} k_{i}^{2}$.

Turn next to stage 2 . For a given and observed $\theta$ and for given investment choices $k_{D}$ and $k_{F}$, in the absence of ISDS the host country government chooses $\nu \in\{0,1\}$ in order to maximize welfare $\Omega^{N}$ as defined in (8). Investments are given and sunk at this point. Assuming firms' subgame perfect output choices, the government's rent is equal to $\pi_{D}^{*}\left(k_{D}\right)-\theta-\frac{1}{2} k_{D}^{2}$ for $\nu=1$, and $-\frac{1}{2} k_{D}^{2}$ for $\nu=0$. The host country government chooses $\nu=1$ if $\pi_{D}^{*}=\frac{k_{D}}{2} \geq \theta$, and it chooses $\nu=0$ if $\pi_{D}^{*}=\frac{k_{D}}{2}<\theta$. Hence, there is a critical size of the externality,

$$
\theta^{*}=\frac{k_{D}}{2},
$$

such that the government allows production if $\theta \leq \theta^{*}$ and bans production if $\theta>\theta^{*}{ }^{14}$

sumer rents change the picture and introduce a further trade-off. The firms also do not compete with each other directly. Such competition would also generate additional interdependencies between the two firms that distract from the effect which is isolated here (see the appendix).

${ }^{14}$ The difficulties for governments to commit and to behave differently than in a timeconsistent optimizing fashion have been discussed in a number of other contexts. Seminal papers are Kydland and Prescott (1977) and Rogoff (1985) in the context of monetary policy, and Kydland and Prescott (1980) in the context of taxation. 
With this decision behavior, the possible producer rent $\pi_{F}^{*}$ of the foreign firm is not accounted for in the government's decision-making. As $\pi_{F}^{*} \geq$ 0 if production is admitted, the threshold $\theta^{*}$ is too low from the point of view of world welfare/efficiency. The government reacts asymmetrically to the investment choices of the two firms. The government's threshold $\theta^{*}$ is a function of firm $D$ 's investment $k_{D}$, but the threshold is independent of firm $F$ 's investment $k_{F}$. The partial reactions of governmental regulation to changes in the domestic and the foreign firm's investment levels are obtained from the partial derivative of $\theta^{*}$ with respect to $k_{D}$ and $k_{F}$. For the domestic firm,

$$
\frac{\partial \theta^{*}}{\partial k_{D}}=\left\{\begin{array}{lll}
\frac{1}{2} & \text { for } & \frac{k_{D}}{2} \in\left(0, \frac{a}{2}\right) \\
0 & \text { for } & \frac{k_{D}}{2}>\frac{a}{2}
\end{array}\right.
$$

For the foreign firm it holds that

$$
\frac{\partial \theta^{*}}{\partial k_{F}}=0
$$

At stage 1 , the true value of $\theta$ is not yet revealed, but firms know the distribution $G(\theta)$ from which the true value of $\theta$ is a random draw. Taking this into consideration and anticipating subgame perfect equilibrium choices at stages 2 and 3, assuming that the firms maximize expected payoffs, the objective functions of the firms at the investment stage are

$$
\begin{aligned}
& \Pi_{D}=G\left(\theta^{*}\left(k_{D}\right)\right) \pi_{D}^{*}\left(k_{D}\right)-K_{D}\left(k_{D}\right) \\
& \Pi_{F}=G\left(\theta^{*}\right) \pi_{F}^{*}\left(k_{F}\right)-K_{F}\left(k_{F}\right) .
\end{aligned}
$$

The first-order condition for firm $D$ is

$$
\frac{\partial \Pi_{D}}{\partial k_{D}}=\left(G\left(\theta^{*}\right) \frac{\partial \pi_{D}^{*}}{\partial k_{D}}-\frac{\partial K_{D}\left(k_{D}\right)}{\partial k_{D}}\right)+G^{\prime}\left(\theta^{*}\right) \frac{\partial \theta^{*}}{\partial k_{D}} \pi_{D}^{*}=0 .
$$

The firm $D$ is 'large' in a strategic sense here, and this is important for the results. The term $G^{\prime}\left(\theta^{*}\right)\left(\partial \theta^{*} / \partial k_{D}\right) \pi_{D}^{*}$ describes how the domestic firm internalizes that its investment choices affects the regulatory decision-making. ${ }^{15}$

\footnotetext{
${ }^{15}$ In industries with many players, the industry faces a collective-good problem: each
} 
Marginal changes in $k_{D}$ affect the expected payoff in a continuous fashion, and $k_{D}$ has strategic value because it affects regulatory policy $\theta^{*} .{ }^{16}$

Using the definition (1), the assumption (2) and $a>5 / 4$, and the results (12), (13), (14) and (15) we note that the objective functions are strictly concave. Maximization of $\Pi_{D}$ for this parametric case yields.

$$
k_{D}^{*}=\frac{a}{4 a-2} .
$$

The critical size $\theta^{*}$ of the externality cost is

$$
\theta^{*}=\frac{1}{2} \frac{a}{4 a-2} .
$$

Note that this equilibrium threshold value $\theta^{*}$ is inside the support of $\theta$, given the assumption about the range of $a$. The first-order condition firm $F$ for the choice of $k_{F}$ that results is

$$
\frac{\partial \Pi_{F}}{\partial k_{F}}=G\left(\theta^{*}\right) \frac{\partial \pi_{F}}{\partial k_{F}}-\frac{\partial K_{F}\left(k_{F}\right)}{\partial k_{F}}=0 .
$$

This yields

$$
k_{F}^{*}=\frac{1}{2} \frac{a-\frac{1}{4}}{2 a-1} .
$$

A comparison between (17) and (20) shows that $\frac{\partial \Pi_{F}}{\partial k_{F}}<0$ if evaluated at $k_{F}=k_{D}^{*}$. Also, a direct comparison of the parametric case with $k_{D}^{*}$ as in (18) and $k_{F}^{*}$ as in (21) confirms that firm $D$ chooses a higher investment than firm $F$. The following proposition summarizes this result:

firm's investment increases $\theta^{*}$, but each firm internalizes only the effect on this firm's own expected profit. As a result, the strategic overinvestment may be less pronounced in such industries. Moreover, the complementarity in the firms' investment behavior may cause multiple equilibria: some in which firms believe that all other firms invest much, and some in which all firms believe that all other firms invest little.

${ }^{16}$ In many contexts the government may regulate firms more gradually, charging a Pigovian tax per unit of output that measures an external cost per unit of output. It can be shown that a strategic investment incentive arises in this case as well if the Pigovian tax rate itself depends on the level of investment $k_{D}$. 
Proposition 1 In the regime without ISDS the domestic firm has a stronger incentive to invest than the foreign firm. The equilibrium investment of the domestic firm is higher than that of the foreign firm: $k_{D}^{*}>k_{F}^{*}$.

The equilibrium investment by firm $D$ causes a reduction of the expected national welfare in the host country from an ex-ante point of view. To see this, let us disregard the activity choice of firm $F$, as this choice does not affect national welfare in the host country in this regime. The domestic welfare is

$$
G\left(\theta^{*}\left(k_{D}\right)\right) \frac{k_{D}}{2}-K_{D}\left(k_{D}\right)-\int_{-\frac{a}{2}}^{\theta^{*}\left(k_{D}\right)} \theta G^{\prime}(\theta) d \theta .
$$

The integral measures the expected externality cost conditional to the decision rule with a threshold $\theta^{*}=k_{D} / 2$. The maximization of (22) with respect to $k_{D}$ yields the first-order condition

$$
G^{\prime}\left(\theta^{*}\right) \frac{k_{D}}{4}+G\left(\theta^{*}\right) \frac{1}{2}-k_{D}-\frac{k_{D}}{2} G^{\prime}\left(\theta^{*}\right) \frac{1}{2}=0
$$

and simplifies to $G\left(\theta^{*}\right) / 2-k_{D}=0$. Invoking the assumption (2), the optimal level is

$$
\tilde{k}_{D}=\frac{a}{4 a-1} .
$$

This investment level, in turn, leads to an ex-post efficient decision rule with a threshold

$$
\tilde{\theta}=\frac{1}{2} \frac{a}{4 a-1} .
$$

A comparison of (18) and (23) and of (19) and (24) yields the following result on welfare:

Proposition 2 The equilibrium in the regime without ISDS is characterized by overinvestment (18) by the domestic firm compared to the investment level (23) that maximizes ex-ante domestic welfare in the host country. This overinvestment leads to time-consistent governmental regulation $\theta^{*}$ that is excessively permissive. 
The proposition highlights the implications of (14) and (15). Firm D's producer rent adds to national welfare. A higher investment increases the producer rent of firm $D$ and makes the government choose a more permissive regulatory policy. A large firm $D$ (or a domestic industry that is able to coordinate on the strategic investment choice) internalizes this strategic effect. Firm $F$ does not have this strategic incentive and, hence, $F$ invests less than $D$. However, the strategic incentive of firm $D$ also matters for $F$. Due to the overinvestment by firm $D$, the governmental policy is more permissive. The firm $F$ anticipates this more permissive regulatory policy when making its own investment choice.

This analysis also shows that the government could address the overinvestment problem ex-ante and implement domestic investment $\tilde{k}_{D}$ that maximizes domestic welfare. This could be achieved by a suitable investment tax that increases the cost of investment, or by direct investment regulation. This investment regulation had to target the investment by $D$ but not the one by $F$, as $F$ does not have an incentive to make strategic overinvestment.

The anecdotal evidence on the investment in nuclear power by domestic, or even state-owned firms in some European countries and its role for the countries' decisions in the aftermath of Chernobyl and Fukujima is greatly in line with this result: it illustrates the potential importance of the size of home government's "ownership" in the stock of capital invested in the domestic industry, how the size of this investment may affect environmental regulation, and how this may affect the investment incentives of large investors.

\section{The equilibrium with ex-post efficient ISDS}

Let us now solve for the equilibrium of the game which emerges with an ISDS regime that implements ex-post efficient regulatory decisions.

Consider stage 3 . The analysis for $\nu=1$ yields output choices $x_{D}^{*}\left(k_{D}\right)=$ $k_{D}$ and $x_{F}^{*}\left(k_{F}\right)=k_{F}$ that are determined by the firms' investment choices $k_{D}$ and $k_{F}$ and producer rents that follow the same functional form as in (12). The amounts $k_{D}$ and $k_{F}$ denote the capital investments in stage 1 and may 
typically differ from the equilibrium values that firms choose in the regime N.

For $\nu=0$, the outcome depends on the size of the externality. If $\theta>\hat{\theta}$ as defined in (5), then the court rules that no compensation will be paid. The payoffs of the firms and the government are then the same as in the absence of ISDS. The existence of ISDS matters for payments if $\nu=0$ and $\theta \leq \hat{\theta}$. In this case the court rules that the government has to pay firm $F$ an amount equal to $\pi_{F}^{*}\left(k_{F}\right)$, and the final payoffs are described by (6) and (9).

Consider the government's decision in stage 2 given that the court applies the rule characterized by the threshold value (5). The government chooses $\nu \in\{1,0\}$ to maximize the country's welfare. The government internalizes the loss of the producer rent of firm $F$ because it has to pay compensation $\pi_{F}^{*}\left(k_{F}\right)$ to $F$ if it bans production in case of $\theta \leq \hat{\theta}$. Furthermore, it internalizes the loss of the producer rent of firm $D$ if it chooses $\nu=0$, as in section 4: this firm's rent is part of the country's welfare. The government chooses to allow production (chooses $\nu=1$ ) if and only if the externality cost does not exceed the sum $\pi_{D}^{*}\left(k_{D}\right)+\pi_{F}^{*}\left(k_{F}\right)$, i.e., if

$$
\theta \leq \hat{\theta}=\frac{k_{D}}{2}+\frac{k_{F}}{2} .
$$

The government's threshold (5) reacts to both firms' investment choices, such that

$$
\frac{\partial \hat{\theta}}{\partial k_{D}}=\frac{\partial \hat{\theta}}{\partial k_{F}}=\left\{\begin{array}{lll}
\frac{1}{2} & \text { for } & \frac{k_{D}}{2}+\frac{k_{F}}{2} \in\left(0, \frac{a}{2}\right) \\
0 & \text { for } & \frac{k_{D}}{2}+\frac{k_{F}}{2}>\frac{a}{2}
\end{array}\right.
$$

Turn to the investment choices in stage 1. The two firms' expected ex-ante profits are

$$
\begin{aligned}
\Pi_{D} & =G(\hat{\theta}) \pi_{D}^{*}\left(k_{D}\right)-K_{D}\left(k_{D}\right) \\
\Pi_{F} & =G(\hat{\theta}) \pi_{F}^{*}\left(k_{F}\right)-K_{F}\left(k_{F}\right) .
\end{aligned}
$$

The payoff functions of both firms take the subgame perfect equilibrium behavior in stages 2 and 3 into account. The probability that the government will allow production is now given by $G(\hat{\theta})$. The first-order conditions are

$$
\frac{\partial \Pi_{D}}{\partial k_{D}}=\left(G(\hat{\theta}) \frac{\partial \pi_{D}^{*}}{\partial k_{D}}-K_{D}^{\prime}\left(k_{D}\right)\right)+G^{\prime}(\hat{\theta}) \frac{\partial \hat{\theta}}{\partial k_{D}} \pi_{D}^{*}\left(k_{D}\right)=0
$$


and

$$
\frac{\partial \Pi_{F}}{\partial k_{F}}=\left(G(\hat{\theta}) \frac{\partial \pi_{F}^{*}}{\partial k_{F}}-K_{F}^{\prime}\left(k_{F}\right)\right)+G^{\prime}(\hat{\theta}) \frac{\partial \hat{\theta}}{\partial k_{F}} \pi_{F}^{*}\left(k_{F}\right)=0 .
$$

Using (1), (2), (9), (12), (5) and (26) and noting that the objective functions are concave, we calculate the optimal reply functions as

$$
k_{i}\left(k_{j}\right)=\left\{\begin{array}{clc}
\frac{a+k_{j}}{4 a-2} & \text { for } & k_{j} \in\left(0, a \frac{4 a-3}{4 a-1}\right) \\
\frac{1}{2} & \text { for } & k_{j}>a \frac{4 a-3}{4 a-1}
\end{array}\right.
$$

The reaction functions (30) show: the investments by the two firms are strategic complements in a wide range. The two reply functions intersect once and only once if $a>\frac{5}{4}$, at

$$
\hat{k}_{D}=\hat{k}_{F}=\frac{a}{4 a-3} .
$$

Proposition 3 The court decision rule with a threshold $\hat{\theta}$ described by (5) implements symmetric investment incentives for both firms and investment levels (31).

The proposition shows that the arbitration court generates an equal level playing field. The asymmetry between the two firms that was described in Proposition 1 disappears. Furthermore, both firms have the same investment incentives, and both firms account for the positive strategic effect of their own investment.

Note further that $\hat{k}>k_{D}^{*}>k_{F}^{*}$ : the capital investment by each firm in the equilibrium with ISDS is higher than in the regime without ISDS. This has several reasons. First, each firm has similar strategic incentives in the ISDS regime as firm $D$ had in the regime without ISDS. Second, due to the ISDS regime the government takes the investment by $F$ into account for its regulatory decisions. This makes the government more permissive in its regulatory decisions. This, in turn, makes it more likely that firms can produce and use their investments, and this increases the firms' marginal expected benefit from additional capital investment. Third, the firms' investment decisions are strategic complements. If firm $F$ invests more, this shifts the 
threshold for $\theta$ and makes it more likely that an investment by $D$ can be used for production.

For the time-consistent, efficiency-oriented regulatory policy

$$
\hat{\theta}=\frac{k_{D}}{2}+\frac{k_{F}}{2}=\hat{k}=\frac{a}{4 a-3}>\theta^{*}
$$

is obtained in the equilibrium. The government tolerates external costs up to an amount of $\hat{\theta}$. Ex ante this means that it permits production with a probability of $G(\hat{\theta})$.

Next let us compare the equilibrium outcome in the ISDS regime with the investment levels that maximize world welfare from an ex-ante perspective. Staying close to section 4 the question is what would the choice of $k_{D}=$ $k_{F} \equiv \tilde{k}^{w}$ be if the host-country government could choose these investment levels. As in section 4, let us assume that the government cannot make a commitment and implements the time-consistent regulatory decision rule as regards the threshold on $\theta$. World welfare is

$$
\begin{aligned}
\Omega^{w}= & G\left(\hat{\theta}\left(\pi_{D}^{*}\left(k_{D}\right)+\pi_{F}^{*}\left(k_{F}\right)\right)\right)\left(\pi_{D}^{*}\left(k_{D}\right)+\pi_{F}^{*}\left(k_{F}\right)\right) \\
& -K_{D}\left(k_{D}\right)-K_{F}\left(k_{F}\right)-\int_{-\frac{a}{2}}^{\hat{\theta}\left(\pi_{D}^{*}\left(k_{D}\right)+\pi_{F}^{*}\left(k_{F}\right)\right)} \theta G^{\prime}(\theta) d \theta .
\end{aligned}
$$

Convexity of $K_{i}\left(k_{i}\right)$ and symmetry implies that the optimum has $k_{D}=k_{F}$. The assumed equality of $k_{D}=k_{F}$ in the optimization problem is an implication of efficient allocation of a given amount of investment between the two firms. Making use of (1), (2), (9), and (5) the maximization of this objective function with respect to $k_{D}$ and $k_{F}$ yields

$$
\tilde{k}^{w}=\frac{a}{4 a-2} .
$$

A comparison between $\hat{k}$ and $\tilde{k}^{w}$ shows that $\hat{k}>\tilde{k}^{w}$ : the equilibrium in a regime with ISDS is characterized by an investment that exceeds the investment that maximizes the expected world welfare at the investment stage.

This result has straightforward implications for the regulatory policy. The government could address the overinvestment problem and implement the 
globally efficient investment level $\tilde{k}^{w}$ if it could tax investment or regulate the two firms' investments directly. This investment regulation would have to address both firms symmetrically. Note also that the government would not have an incentive to implement this $\tilde{k}^{w}$ as it maximizes domestic welfare and not global welfare (33). ${ }^{17}$

Stated as a proposition:

Proposition 4 The equilibrium in the regime with ISDS is characterized by overinvestment by both firms compared to the investment levels that maximizes ex-ante world welfare. This overinvestment leads to governmental regulation that is ex-post efficient, but is more permissive than the regulation that emerges from ex-ante efficient investment.

\section{Comparing the two regimes}

It remains here to compare the two regimes from the point of view of the distribution of rents and of world welfare. Consider regulatory leniency. Comparing $\theta^{*}$ as in (19), $\tilde{\theta}$ as in (24), $\hat{\theta}$ as in (5) and $\tilde{\theta}^{w}$ as in (34) this yields:

$$
0<\tilde{\theta}<\theta^{*}<\hat{\theta}\left(\tilde{k}^{w}\right)<\hat{\theta}(\hat{k}) .
$$

The regulatory policy is more permissive in the equilibrium in the regime with ISDS than in the equilibrium in the regime without ISDS. Therefore, in expectation, the regime with ISDS creates higher external costs. The equilibrium quantities can be used to calculate firm profits and to confirm that

$$
\Pi_{D}^{*}=\frac{1}{16} \frac{a}{2 a-1}<\frac{1}{4} a \frac{2 a-1}{(4 a-3)^{2}}=\Pi_{D}^{I S D S}
$$

\footnotetext{
${ }^{17}$ The investment regulation incentives of the government could possibly be manipulated by the design of the compensation rule in the ISDS regime. However, such a custom-made, industry-specific compensation rule faces major practicability problems. The compensation rule had to account for industry-specific characteristics, such as market concentration, that determine the strength of the strategic investment incentives. Such a regime is seemingly more difficult to implement than a compensation rule that is guided by ex-post efficiency. The latter rule gives the arbitration court a conceptually clear guideline that could be applied universally.
} 
for all $a$ in the permissible range. The ISDS regime also benefits the domestic firm $D$.

Let us consider world welfare in the two regimes. Global welfare is the sum of both firms' expected profits minus the expected externality cost. Without ISDS this welfare is given by the sum

$$
G\left(\theta^{*}\right)\left(\pi_{D}^{*}\left(k_{D}^{*}\right)+\pi_{F}^{*}\left(k_{F}^{*}\right)-E\left(\theta \mid \theta \leq \theta^{*}\right)\right)-K_{D}\left(k_{D}^{*}\right)-K_{F}\left(k_{F}^{*}\right),
$$

and with ISDS, the corresponding sum is

$$
G(\hat{\theta})\left(\pi_{D}^{*}\left(\hat{k}_{D}\right)+\pi_{F}^{*}\left(\hat{k}_{F}\right)-E(\theta \mid \theta \leq \hat{\theta})\right)-K_{D}\left(\hat{k}_{D}\right)-K_{F}\left(\hat{k}_{F}\right) .
$$

Inserting the equilibrium values and comparing the resulting international welfare levels shows that the international welfare is higher in the regime with ISDS if

$$
\frac{1}{128} \frac{64 a^{3}-144 a^{2}+76 a-9}{(2 a-1)^{2}(4 a-3)^{2}}>0 .
$$

For $a>5 / 4$, the polynomial $64 x^{3}-144 x^{2}+76 x-9$ is negative in the range $a \in(1.25 ; 1.5369)$, and it is positive in the range for $a>1.5369$. The welfare cost of strategic investment exceeds the welfare benefits from equalling the level playing field in the lower range of $a$, i.e., the range in which the strategic investment incentives are sufficiently strong.

\section{Discussion and conclusions}

This paper shows that ISDS may have a dark side, even if it works perfectly in the sense that the mechanism operates without transaction costs in an environment with perfect and complete information, and if the court decisions are designed such that they implement regulatory behavior by the government that maximizes world welfare ex post. The ISDS regime induces additional, strategically motivated investment.

This incentive is not a Pigovian market failure. It is caused not by externalities or other sources of market failure in the private markets. Also the overinvestment is not caused by a non-benevolent government in the tradition of public choice. The market is characterized by perfect competition and 
the government is fully efficiency-oriented. It is the government's efficiency orientation itself that generates the problem. The strategic overinvestment is triggered by time-consistent optimizing behavior of an efficiency oriented regulator and its inability to commit to adopting a regulatory policy in the future that would be inefficient at the time of implementation.

The key findings can be summarized: (1) In the absence of ISDS, the domestic firm has an incentive for strategic overinvestment. (2) ISDS can induce strategic overinvestment by the foreign firm. (3) The two strategic overinvestment incentives are strategic complements and induce even higher capital investment. (4) Both the domestic and the foreign firm benefit from the ISDS regime. (5) Depending on the strength of the strategic investment incentives, world welfare may be lower or higher in the regime with ISDS than in a regime without ISDS.

\section{Appendix}

This appendix considers a more general model. It shows that the strategic investment incentives show up and that ISDS makes also a difference in this more general model. The basic overinvestment effects may be superimposed by additional effects, such as consumer rent effects and the market interdependency between the firms.

The basic decision structure and the choice variables are as in the parametric model: firms $D$ and $F$ simultaneously choose their capital investments $k_{D}$ and $k_{F}$, which has convex costs $K_{D}\left(k_{D}\right)$ and $K_{F}\left(k_{F}\right)$ in stage 1 . Next, the value of the externality $\operatorname{cost} \theta$ is revealed. This $\theta$ is drawn from a random distribution with the cumulative distribution function $G(\theta)$. Next, in stage 2 , the government chooses whether to allow or ban production. If production is banned, without ISDS the game ends. In the regime with ISDS, however, compensation for the lost producer rent might be paid to $F$. Compensation is paid if and only if the decision to ban is inefficient with respect to aggregate welfare at the point of decision-making. In stage 3 , if production is allowed, $D$ and $F$ make their market/production choices to maximize their 
producer rents. Rather than considering a specific micro-structured market model, let the subgame equilibrium producer rents be given as $\pi_{D}^{*}\left(k_{D}, k_{F}\right)$ and $\pi_{F}^{*}\left(k_{D}, k_{F}\right)$. Suppose that these are twice continuously differentiable, increasing and concave in a firm's own capital investment, and weakly decreasing in the other firm's capital investment. Furthermore, let the function $H\left(k_{D}, k_{F}\right)$ describe the consumer rent that emerges in the market in case of production. Let this consumer rent go to the host country. Also, let $H$ be twice continuously differentiable. Note that it cannot be taken for granted that $H$ is locally increasing in both $k_{D}$ and $k_{F}$ on its whole domain.

Suppose there is no ISDS in operation. The government maximizes domestic welfare in stage 2 . It allows production if

$$
\theta \leq \theta^{*}\left(k_{D}, k_{F}\right)=\pi_{D}^{*}\left(k_{D}, k_{F}\right)+H\left(k_{D}, k_{F}\right)
$$

This shows that

$$
\frac{\partial \theta^{*}}{\partial k_{D}}=\frac{\partial \pi_{D}^{*}}{\partial k_{D}}+\frac{\partial H}{\partial k_{D}} \text { and } \frac{\partial \theta^{*}}{\partial k_{F}}=\frac{\partial \pi_{D}^{*}}{\partial k_{F}}+\frac{\partial H}{\partial k_{F}} .
$$

In stage 1 the domestic firm $D$ chooses $k_{D}$ to maximize

$$
G\left(\theta^{*}\left(k_{D}, k_{F}\right)\right) \pi_{D}^{*}\left(k_{D}, k_{F}\right)-K_{D}\left(k_{D}\right)
$$

This yields the first-order condition

$$
\left(G\left(\theta^{*}\right) \frac{\partial \pi_{D}^{*}}{\partial k_{D}}-K_{D}^{\prime}\left(k_{D}\right)\right)+G^{\prime}\left(\theta^{*}\right)\left[\frac{\partial \pi_{D}^{*}}{\partial k_{D}}+\frac{\partial H}{\partial k_{D}}\right] \pi_{D}^{*}\left(k_{D}, k_{F}\right)=0 .
$$

The last term that starts with $G^{\prime}\left(\theta^{*}\right)$ measures the strategic effect of investment. The foreign firm maximizes

$$
G\left(\theta^{*}\left(k_{D}, k_{F}\right)\right) \pi_{F}^{*}\left(k_{D}, k_{F}\right)-K_{F}\left(k_{F}\right)
$$

and this yields the first-order condition

$$
\left(G\left(\theta^{*}\right) \frac{\partial \pi_{F}^{*}}{\partial k_{F}}-K_{F}^{\prime}\left(k_{F}\right)\right)+G^{\prime}\left(\theta^{*}\right)\left[\frac{\partial \pi_{D}^{*}}{\partial k_{F}}+\frac{\partial H}{\partial k_{F}}\right] \pi_{F}^{*}\left(k_{D}, k_{F}\right)=0 .
$$


The conditions reveal possible differences in the marginal investment incentives. ${ }^{18}$ Both firms may affect $\theta^{*}$ through their capital investment, as this investment may affect the consumer rent $H$ and firm $D$ 's producer rent. Firm $D$ can increase $\theta^{*}$ via the positive effect of $k_{D}$ on $\pi_{D}^{*}$, and firm $F$ 's investment may (weakly) decrease $\theta^{*}$ via the effect of $k_{F}$ on $\pi_{D}^{*}$. For symmetric firms $D$ and $F$, this implies $k_{D}^{*}>k_{F}^{*}$ unless the effect via $H\left(k_{D}, k_{F}\right)$ counteracts and outweighs the effects via profits.

One set of assumptions that yields an interior equilibrium with $k_{D}^{*}>k_{F}^{*}$ is the one in the main analysis where $\pi_{i}\left(k_{i}, k_{j}\right)$ is given by $(12), K_{i}\left(k_{i}\right)$ is given by $(1), G(\theta)$ is given by $(2)$ and $H\left(k_{D}, k_{F}\right)$ is zero.

Another interesting case that leads to qualitatively similar results as in the analysis in sections 3-6 is the case of symmetric independent monopoly firms. This case emerges for the following more specific structure: $(1) \pi_{i}^{*}\left(k_{i}, k_{j}\right)=$ $\pi\left(k_{i}\right)$ and independent of the other firm's investment. (2) Firms $D$ and $F$ have the same cost function: $K_{D}(k)=K_{F}(k) \equiv K(k)$. (3) Consumer rent is $H\left(k_{D}, k_{F}\right)=h\left(k_{D}\right)+h\left(k_{F}\right)$ and $h$ is a concave function. (4) The distribution function $G(\theta)$ is uniform with $G^{\prime} \equiv g$ on its (sufficiently large) support. In this case the first-order conditions for $D$ and $F$ in the regime without ISDS reduce to

$$
\left[G\left(\theta^{*}\right) \pi^{\prime}\left(k_{D}\right)-K^{\prime}\left(k_{D}\right)\right]+G^{\prime}\left(\theta^{*}\right)\left[\pi^{\prime}\left(k_{D}\right)+h^{\prime}\left(k_{D}\right)\right] \pi\left(k_{D}\right)=0
$$

and

$$
\left[G\left(\theta^{*}\right) \pi^{\prime}\left(k_{F}\right)-K^{\prime}\left(k_{F}\right)\right]+G^{\prime}\left(\theta^{*}\right) h^{\prime}\left(k_{F}\right) \pi\left(k_{F}\right)=0 .
$$

Suppose these first-order conditions determine the equilibrium. Let $k_{F}^{*}$ be the investment that fulfills firm $F^{\prime}$ 's first-order condition with equality. Then the marginal payoff of firm $D$ evaluated at $k_{D}=k_{F}^{*}$ is $G^{\prime}\left(\pi\left(k_{F}^{*}\right)+2 h\left(k_{F}^{*}\right)\right) \pi^{\prime}\left(k_{F}^{*}\right) \pi\left(k_{F}^{*}\right)>$ 0 , and this implies $k_{D}^{*}>k_{F}^{*}$.

Suppose now ISDS is in operation. The ISDS regime induces compensation for the loss in producer rent for $F$ if the government bans production if

\footnotetext{
${ }^{18}$ The discussion assumes that the first-order conditions apply in the equilibrium. Of couse, without more specific assumptions this cannot be taken for granted.
} 
this decision does not maximize aggregate welfare at this stage. This determines the threshold

$$
\hat{\theta}\left(k_{D}, k_{F}\right) \equiv \pi_{D}^{*}\left(k_{D}, k_{F}\right)+\pi_{F}^{*}\left(k_{F}, k_{D}\right)+H\left(k_{D}, k_{F}\right) .
$$

Compensation is paid if the production is banned for $\theta \leq \hat{\theta}$ and no compensation is paid in all other cases. The threshold value for a favorable regulatory decision in (47) is increasing not only in the domestic firm's producer rent and in consumer surplus, but also in the producer rent of the foreign firm. A higher $k_{F}$ will typically increase $\pi_{F}^{*}$. This effect works in favor of an increase of the threshold towards a more lenient regulation of production. It also reveals a complementarity between domestic and foreign investment. Furthermore, $k_{F}$ may change $H$ and $\pi_{D}^{*}$. The direction of these effects depends on the interaction of the two firms in the market and may strengthen or weaken the complementarity.

The first-order conditions for the choice of capital investment for the domestic firm and the foreign firm are

$$
\begin{aligned}
& \left(G(\hat{\theta}) \frac{\partial \pi_{D}^{*}}{\partial k_{D}}-K_{D}^{\prime}\right)+G^{\prime}(\hat{\theta})\left[\frac{\partial \pi_{D}^{*}}{\partial k_{D}}+\frac{\partial \pi_{F}^{*}}{\partial k_{D}}+\frac{\partial H}{\partial k_{D}}\right] \pi_{D}^{*}\left(k_{D}, k_{F}\right)=0 \\
& \left(G(\hat{\theta}) \frac{\partial \pi_{F}^{*}}{\partial k_{F}}-K_{F}^{\prime}\right)+G^{\prime}(\hat{\theta})\left[\frac{\partial \pi_{D}^{*}}{\partial k_{F}}+\frac{\partial \pi_{F}^{*}}{\partial k_{F}}+\frac{\partial H}{\partial k_{F}}\right] \pi_{F}^{*}\left(k_{D}, k_{F}\right)=0
\end{aligned}
$$

The first term in brackets in (48) measures expected marginal producer rent minus the marginal cost of an additional unit of investment for a given value of $\hat{\theta}$. The last term measures the strategic effect: a change in a firm's investment affects regulatory leniency. The marginal conditions in (48) that govern the capital investment of the two firms are structurally identical for the two firms. Hence, if the firms are symmetric and the first-order conditions determine the equilibrium, it will be characterized by identical amounts of investment: $k_{D}=k_{F}=\hat{k}$.

For the case with symmetric independent monopolies the first-order conditions can be written as

$$
\left(G(\hat{\theta}) \pi^{\prime}\left(k_{D}\right)-K^{\prime}\left(k_{D}\right)\right)+G^{\prime}(\hat{\theta})\left[\pi^{\prime}\left(k_{D}\right)+h^{\prime}\left(k_{D}\right)\right] \pi\left(k_{D}\right)=0,
$$


and

$$
\left(G(\hat{\theta}) \pi^{\prime}\left(k_{F}\right)-K^{\prime}\left(k_{F}\right)\right)+G^{\prime}(\hat{\theta})\left[\pi^{\prime}\left(k_{F}\right)+h^{\prime}\left(k_{F}\right)\right] \pi\left(k_{F}\right)=0 .
$$

Consider now whether $\hat{k}>k_{D}^{*}$. Using $G^{\prime}()=$.$g (and limiting considera-$ tion to the interior range in which this applies) we re-write the left-hand side of (49) as

$$
G\left(\theta^{*}\left(k_{D}, k_{F}\right)\right) \pi^{\prime}\left(k_{D}\right)+A\left(k_{D}\right)
$$

with $A\left(k_{D}\right) \equiv-K^{\prime}\left(k_{D}\right)+g\left[\pi^{\prime}\left(k_{D}\right)+h^{\prime}\left(k_{D}\right)\right] \pi\left(k_{D}\right)$ and the left-hand side of (45) as

$$
G\left(\hat{\theta}\left(k_{D}, k_{F}\right)\right) \pi^{\prime}\left(k_{D}\right)+A\left(k_{D}\right) .
$$

By the definition of $\left(k_{D}^{*}, k_{F}^{*}\right)$, the term (51) equals zero at $\left(k_{D}^{*}, k_{F}^{*}\right)$. Furthermore, it was shown that $k_{D}^{*}>k_{F}^{*}$. Note that $\theta^{*}\left(k_{D}, k_{F}\right)$ is increasing in $k_{F}$. This implies that $G\left(\theta^{*}\left(k_{D}, k_{F}\right)\right) \pi^{\prime}\left(k_{D}\right)+A\left(k_{D}\right)>0$ at $\left(k_{D}, k_{F}\right)=\left(k_{D}^{*}, k_{D}^{*}\right)$. Note further that $\theta^{*}\left(k_{D}, k_{F}\right)<\hat{\theta}\left(k_{D}, k_{F}\right)$ for strictly positive values of $k_{D}$ and $k_{F}$. So we can conclude that

$$
G\left(\hat{\theta}\left(k_{D}, k_{F}\right)\right) \pi^{\prime}\left(k_{D}\right)+A\left(k_{D}\right)>G\left(\theta^{*}\left(k_{D}, k_{F}\right)\right) \pi^{\prime}\left(k_{D}\right)+A\left(k_{D}\right)>0
$$

at $\left(k_{D}, k_{F}\right)=\left(k_{D}^{*}, k_{D}^{*}\right)$. This implies that the value of $\left(k_{D}, k_{F}\right)=(\hat{k}, \hat{k})$ that solves the symmetric conditions (49) and (50) must have $\hat{k}>k_{D}^{*}$.

As a conclusion from this appendix, investments of firms may affect regulatory decision-making through a number of channels. In the regime with ISDS the government also accounts for the foreign firm's rent. ISDS will generally make a difference. However, indirect effects of a firm's investment via consumer rents or via the other firm's equilibrium producer rents make quantitative predictions less straightforward. If these additional effects are small or absent (as in the two special cases considered), overinvestment occurs, and is stronger in a regime with ISDS.

\section{References}

[1] Aisbett, Emma, Larry Karp, and Carol McAusland, 2010a, Copensation for indirect expropriation in international investment agreements, 
implications for national treatment and rights to invest, Journal of Globalization and Development, 1(2), Article 6.

[2] Aisbett, Emma, Larry Karp, and Carol McAusland, 2010b, Police powers, regulatory takings and the efficient compensation of domestic and foreign investors, Economic Record, 86(274), 367-383.

[3] Bernasconi-Osterwalder, Nathalie, and Martin D. Brauch, 2014, The state of play in Vattenfall v. Germany II: leaving the German public in the dark, The International Institute for Sustainable Development.

[4] Blonigen, Bruce A., and David N. Figlio, 1998, Voting for protection: does direct foreign investment influence legislator behavior?, American Economic Review, 88(4), 1002-1014.

[5] Blume, Lawrence, Daniel L. Rubinfeld, and Perry Shapiro, 1984, The taking of land: When should compensation be paid?, Quarterly Journal of Economics, 99(1) 71-92.

[6] Casella, Alessandra, 1996, On market integration and the development of institutions: the case of international commercial arbitration, European Economic Review, 40(1), 155-186.

[7] Cole, Harold L., and William B. English, 1991, Expropriation and direct investment, Journal of International Economics, 30(3-4), 201-227.

[8] Cole, Matthew A., Robert J. R. Elliott and Per G. Fredriksson, 2006, Endogenous pollution havens: Does FDI influence environmental regulations? Scandinavian Journal of Economics, 108(1), 157-178.

[9] Cutler, David M., and Keith M. Marzilli Ericson, 2010, Costeffectiveness analysis in markets with high fixed costs, Pharmacoeconomics, 28(10) Special Issue: SI, 867-875.

[10] Damania, R., 2001, When the weak win: the role of investment in environmental lobbying, Journal of Environmental Economics and Management, 42(1), 1-22.

[11] Dijkstra, Bouwe R., 2007, An investment contest to influence environmental policy, Resource and Energy Economics, 29, 300-324. 
[12] Dixit, Avinash, 2011, International trade, foreign direct investment, and security, Annual Review of Economics, 3(1), 191-213.

[13] Eaton, Jonathan, and Mark Gersovitz, 1983, Country risk: economic aspects, In: R. J. Herring, ed., Managing International Risk, Cambridge University Press, Cambridge, 75-108.

[14] Franck, Susan D., and Lindsey E. Wylie, 2015, Predicting outcomes in investment treaty arbitration, Duke Law Journal, 65, 459-525.

[15] Glazer, Amihai, and Eckhard Janeba, 2004, Strategic investment by a regulated firm, International Tax and Public Finance, 11, 123-132.

[16] Horn, Henrik, and Thomas Tangerås, 2016, Economics and politics of international investment agreements, IFN Working Paper No. 1140, November 2016.

[17] Huck, Steffen, and Kai A. Konrad, 2005, Moral cost, commitment, and committee size, Journal of Institutional and Theoretical Economics, 161(4), 575-588.

[18] Janeba, Eckhard, 2000, Tax competition when governments lack commitment: Excess capacity as a countervailing threat, American Economic Review, 90(5), 1508-1519.

[19] Janeba, Eckhard, 2016, Regulatory chill and the effect of investor state dispute settlements, unpublished manuscript.

[20] Kohler, Wilhelm, and Frank Stähler, 2016, The economics of investor protection: ISDS versus National Treatment, CESifo Working Paper no. 5766 .

[21] Konrad, Kai A., and Kjell E. Lommerud, 2001, Foreign direct investment, intra-firm trade and ownership structure, European Economic Review, 45(3), 475-494.

[22] Kydland, Finn E., and Edward C. Prescott, 1977, Rules rather than discretion: the inconsistency of optimal plans, Journal of Political Economy, 85(3), 473-491. 
[23] Kydland, Finn E., and Edward C. Prescott, 1980, Dynamic optimal taxation, rational expectations and optimal control, Journal of Economic Dynamics and Control, 2, 79-91.

[24] Mattli, Walter, 2001, Private justice in a global economy: from litigation to arbitration, International Organization, 55(4), 919-947.

[25] Olsen, Trond E., and Petter Osmundsen, 2003, Spillovers and international competition for investments, Journal of International Economics, 59(1), 211-238.

[26] Quick, Reinhard, 2015, Why TTIP should have an investment chapter including ISDS, Journal of World Trade, 49(2), 199-209.

[27] Rivkin, David W., Sophie J. Lamb, and Nicola K. Leslie, 2015, The future of investor-state dispute settlement in the energy sector: engaging with climate change, human rights and the rule of law, Journal of World Energy Law and Business, 8(2), 130-153.

[28] Robinson, Elisabeth J.Z., 2005, Reassessing the interaction between investment and tenure uncertainty, Environment and Development Economics, 10(2), 143-157, Part 2.

[29] Rogoff, Kenneth, 1985, The optimal degree of commitment to an intermediate monetary target, Quarterly Journal of Economics, 100(4), 1169-1189.

[30] Sappideen, Razeen, and Ling Ling He, 2015, Dispute resolution in investment treaties: balancing the rights of investors and host states, Journal of World Trade, 49(1), 85-116.

[31] Schneider, Mycle, and Antony Patrick Froggatt, 2014, The World Nuclear Industry Status Report, A Mycle Schneider Consulting Project, Paris, London and Washington D.C.

[32] Stähler, Frank, 2016, An optimal investor state dispute settlement mechanism, University of Tübingen, mimeo.

[33] Thomas, Jonathan, and Tim Worrall, 1994, Foreign direct investment and the risk of expropriation, Review of Economic Studies, 61(1), 
81-108.

[34] von Bogdandy, Armin, and Ingo Venzke, 2014, In wessen Namen?: Internationale Gerichte in Zeiten globalen Regierens, Suhrkamp Verlag, Berlin.

[35] Unctad, 2016, World Investment Report 2016, United Nations Publication, Geneva. 